\title{
The societal costs of femoral neck fracture patients treated with internal fixation
}

Stephanie M. Zielinski ${ }^{1}$, Clazien A.M. Bouwmans ${ }^{2}$, Martin J. Heetveld ${ }^{3}$, Mohit Bhandari ${ }^{4}$, Peter Patka ${ }^{5}$, Esther M.M. Van Lieshout ${ }^{1}$, on behalf of the FAITH trial investigators*

${ }^{1}$ Dept. of Surgery-Traumatology, Erasmus MC, University Medical Center Rotterdam, P.O. Box 2040, 3000 CA Rotterdam, the Netherlands

${ }^{2}$ Institute for Medical Technology Assessment, Erasmus University Rotterdam, P.O. Box 1738, 3000 DR Rotterdam

${ }^{3}$ Dept. of Surgery, Kennemer Gasthuis, P.O. Box 417, 2000 AK, Haarlem, the Netherlands

${ }^{4}$ Dept. of Clinical Epidemiology and Biostatistics, McMaster University, HSC 2C, 1200 Main Street West, Hamilton, ON, L8N 3Z5, Canada

${ }^{5}$ Dept. of Emergency Medicine, Erasmus MC, University Medical Center Rotterdam, P.O. Box 2040, 3000 CA Rotterdam, the Netherlands

Corresponding author:

E.M.M. van Lieshout, PhD

Erasmus MC, University Medical Center Rotterdam

Department of Surgery-Traumatology

P.O. Box 2040

3000 CA Rotterdam

The Netherlands

Phone: +31.10.7031050

Fax: +31.10 .7032396$

E-mail: e.vanlieshout@erasmusmc.nl 


\section{Funding}

Members of the research team received a grant from Fonds NutsOhra (grant number T-060243), The Netherlands Organization for Health Research and Development (ZonMw; grant number 171102008), Physicians' Services Incorporated Foundation (grant number 08-18), Canadian Institutes of Health Research (grant number 177466) and National Institutes of Health (grant number 1R01-AR055267-01A1). The funding agencies were not involved in the study design, data collection, data analysis, manuscript preparations or publication decisions for this manuscript. 


\section{Mini abstract}

The study rationale was to provide a detailed overview of the costs for femoral neck fracture treatment with internal fixation in the Netherlands. Mean total costs per patient at two years follow-up were $€ 19,425$. Costs were higher for older, less healthy patients. Results are comparable to internationally published costs. 


\section{Abstract}

Purpose: The aim of this study was to provide a detailed overview of the cost and healthcare consumption of patients treated for a hip fracture with internal fixation. A secondary aim was to compare costs of patients who underwent a revision surgery with patients who did not.

Methods: The study was performed alongside the Dutch sample of an international randomized controlled trial, concerning femoral neck fracture patients treated with internal fixation. Patient characteristics and healthcare consumption were collected. Total follow-up was two years. A societal perspective was adopted. Costs included hospital costs during primary stay and follow-up, and costs related to rehabilitation and changes in living situation. Costs were compared between non-revision surgery patients, implant removal patients, and revision arthroplasty patients.

Results: A total of 248 patients were included (mean age 71 years). Mean total costs per patient at two years follow-up were $€ 19,425$. In the non-revision surgery patients total costs were $€ 17,405(\mathrm{~N}=137)$, in the implant removal patients $€ 10,066(\mathrm{~N}=38)$, and in the revision arthroplasty patients $€ 26,733$ ( $\mathrm{N}=67$ ). The main contributing costs were related to the primary surgery, admission days, physical therapy, and revision surgeries.

Conclusions: The main determinant was the costs of admission to a rehabilitation center/nursing home. Costs were specifically high in elderly with comorbidity, who were less independent pre-fracture, and have a longer admission to the hospital and/or a nursing home. Costs were also higher in revision surgery patients. The two years follow-up costs in our study were comparable to published costs in other Western societies.

Keywords: costs, healthcare consumption, internal fixation, hip fracture, femoral neck fracture 


\section{Introduction}

The worldwide incidence of hip fractures is increasing from an estimated 1.26 million patients per year in 1990, 1.6 million in 2000, to an estimated 4.5-6.3 million by 2050 [1-3]. Accordingly, the incidence of hip fractures in the Netherlands increased from 7,614 per year in 1981 to 21,000 per year in 2010 [4, 5]. Globally, the annual estimated worldwide direct and indirect costs of hip fractures amounted to $\$ 34.8$ billion in 1990, and are expected to rise to an estimated \$131 billion by 2050 [2].

Detailed information on healthcare costs are gaining importance as the burden of health care costs threatens to exceed the financial resources available. It is therefore necessary to focus on options to cut down health care expenses. Costs of hip fracture treatment should receive attention, as hip fractures account for over two third of all hospital admission days due to fractures, the incidence is increasing worldwide, and hip fracture treatment leads to substantial costs. In the Netherlands, the total costs of hip fractures amounted to $€ 13.600$ per patient in 1999 [6]. This was a crude estimate of costs based on national databases and registrations, concerning costs of hip fracture patients, treated with various implants and prostheses. A number of studies compared the costs of treatment with internal fixation with costs of treatment with arthroplasty [7-13]. These studies demonstrated either similar or higher costs for patients treated with internal fixation, ranging from $€ 13,000$ to $€ 57,197$ per patient after a two-year follow-up period (Table 1). Comparison between the studies is impeded however by the differences in follow-up period and in the costs that were studied. In some studies costs were confined to in-hospital health care costs, whereas other studies also included costs caused by rehabilitation or changes in living situation. The studies are often based on limited patient numbers. It is therefore likely that the presented costs are not all a correct estimation of the actual costs involved. To the best of our knowledge, detailed analysis 
of the costs of internal fixation for hip fractures in the Netherlands has never been performed. In the Netherlands, hip fracture care pathways are implemented in an increasing number of hospitals, promoting early mobilization, early hospital discharge, and rehabilitation in a specialized nursing home department or at home. These pathways are designed to optimize patient care and health care cost.

The aim of this study was to provide a detailed overview of the costs of patients with a femoral neck fracture treated with internal fixation. A societal perspective was adopted, including costs of health care and costs incurred outside health care. This information can be used for economic evaluations. A secondary aim was to compare costs of patients who underwent a revision surgery with patients who did not, to study the burden of extra costs caused by revision surgeries. 


\section{Patients and Methods}

This cost study was a cohort study performed alongside the Dutch sample of the FAITH trial (Fixation using Alternative Implants for the Treatment of Hip fractures, NCT00761813), an international randomized controlled trial concerning femoral neck fracture patients treated with internal fixation. The study was approved by the local medical research ethics committee.

\section{Population}

In the Netherlands 14 hospitals participated and enrolled 250 consecutive patients in the period between February 2008 and August 2009. Patients were eligible if they (1) were adults aged $\geq 50$ years, (2) had a radiologically confirmed femoral neck fracture (i.e., either undisplaced fracture, or displaced fracture in ASA 1-2 patients (American Society of Anesthesiologists classification) aged 50-80 years with a fracture that could be reduced closed), (3) had a low energy fracture without other major trauma, and (4) were ambulatory pre-fracture (with or without aid). Patients were excluded if they (1) had a fracture not suitable for internal fixation (e.g,. pathological fracture, rheumatoid arthritis, or osteoarthritis), (2) had associated major injuries of the lower extremities, (3) had retained hardware around the hip, (4) had an infection around the hip, (5) had a bone metabolism disorder other than osteoporosis, (6) were moderately or severely cognitively impaired prefracture, (7) had dementia or Parkinson's disease severe enough to compromise the rehabilitation process, or (8) were not likely to be able to complete follow-up.

Treatment and follow-up 
All patients had medical optimization before surgery. Patients with undisplaced fractures were treated within seven days of presentation, patients with displaced fractures within two days. Patients were treated with internal fixation (i.e., either two or three cancellous screws or a sliding hip screw). Early mobilization was encouraged, with weight bearing as tolerated. Postoperative osteoporosis screening and treatment was recommended in all patients. Follow-up measurements were performed at 2 weeks, 10 weeks, 6 months, 9 months, 12 months, 18 months, and 24 months after the primary surgery.

\section{Cost measurement}

The study adopted a societal perspective including the following costs: (1) hospital costs during the primary stay, (2) hospital costs during follow-up including cost of hip-related adverse events and revision surgeries, and (3) non-hospital costs of rehabilitation and aids. (Table 2). Data on resource use were collected prospectively at the scheduled follow-up contacts and at the close-out visits at the end of the study. Use of hospital resources was collected in the study case report forms (items are listed in supplemental Table 1), and from the patient's hospital file. The latter had 100\% capture. These data were supplemented with data from a patient self-administered questionnaire, a customized version of the 'Trimbos and iMTA questionnaire on Costs associated with Psychiatric illness’ (Tic-P), which has been validated for use in healthcare cost studies $[14,15]$. An English version of the original Tic-P is available online [16].The questionnaire included questions on stay in a rehabilitation center or nursing facility, number of contacts with the medical specialist and physical therapist, medication and the use of aids (e.g., walker, crutches, and wheelchair). The total number of consumption units per cost category per patient was multiplied by the unit prices. The unit prices (anno 2010) for all cost categories are presented in Table 2. The costs for use of the operating room, including cost for personnel, anesthesia, and overhead costs, as well as 
implant and general equipment costs were calculated based on data derived from one of the participating academic hospitals and three regional hospitals, and one surgical equipment and implant firm. Means were calculated and considered a realistic estimation of the average prices in the participating sites.

For most other healthcare resources reference cost prices were derived from the Dutch manual on cost research, methods and standard costs in economic healthcare evaluations (17). Costs from 2008 and 2009 were adjusted to 2010 terms using the national consumer price index. Unit prices for radiologic and other diagnostic procedures were taken from the NZa (Nederlandse Zorgautoriteit; Dutch Healthcare Authority) which are assumed to provide a good indication of the actual costs. Medication costs were calculated using standard medication prices as described by the CVZ (College voor zorgverzekeringen; Health Care Insurance Board), online available on www.medicijnkosten.nl (Supplemental Table 2). The costs for the use of several aids (i.e., crutches, walker, or extra facilities at home) were obtained from at a home care firm that is representative of the Dutch market. These costs were used as an estimation of the actual costs for the use of aids in all participating patients, as these costs are fairly standard and will not vary to a large extent across the country. Costs of aids were calculated according to the annuity method, applying an interest rate of $4.5 \%$ and a 10-year write off period.

Over $90 \%$ of the study population consisted of retired elderly. Consequently, the indirect costs due to productivity losses were considered less relevant for this population and a minor contribution to the overall costs in this study, and were excluded. Costs of home care were also excluded from the analyses. Most elderly patients that received home care were not capable of estimating the amount of hours that they received home care. Moreover, it was impossible to discriminate home care due to the hip fracture from home care for other medical reasons. Reliable cost calculations were therefore impossible. Costs of osteoporosis screening 
and treatment were included, but not presented as a separate group: costs of a DEXA scan were included in radiology/diagnostic studies costs, costs of visits to an osteoporosis specialist were included in outpatient clinic visits costs, and costs for osteoporosis treatment were included in medication costs.

\section{Statistical analysis}

Analyses were performed using SPSS (version 16.0, SPSS Inc., Chicago, IL, USA). Missing values for cost items were replaced using multiple imputation following the predictive mean matching method, using ten imputations. Means and standard deviations (SD) were calculated. Costs were calculated in the total population and in three subgroups (1) patients who did not require a revision surgery, (2) patients who had their implant removed (without any other revision surgery), and (3) patients who underwent one or multiple revision surgeries. Group 2 consisted of patients with a successfully healed fracture. Patients who had other, less common, revision surgeries (i.e., replacement of implant by other implant, shorter screw, or revision to gamma nail) were not included in these subgroup-analyses. Costs between the subgroups were compared with a one-way ANOVA. Post-hoc comparisons using independent samples student T-tests were performed. 


\section{Results}

\section{Demographic description of patients}

Of the 649 consecutive femoral neck fracture patients treated in the study period, 294 patients were eligible following the inclusion and exclusion criteria for this study, of which 250 were randomized (Figure 1). Two patients could not be followed; one patient turned out not to have a femoral neck fracture and one patient withdrew consent immediately after randomization.

The study group had a mean age of 71 years (SD 10) and 60\% was female. Patients were relatively healthy and independent pre-fracture. Prior to the fracture only $3 \%$ of the patients were institutionalized and 13\% used an aid for mobilization. Thirteen percent had severe comorbidities (i.e., ASA>2). The most common comorbidities were hypertension (42\%), cardiac disease (21\%), or pulmonary disease (16\%). Forty-six percent of the fractures was displaced (i.e., Garden III-IV) and 35\% was a Pauwels 3 fracture.

\section{Treatment and clinical outcome}

Patients were admitted to the hospital during 7 days on average. After discharge, $22 \%$ percent of the patients rehabilitated in a nursing home, whereas $72 \%$ of the patients were able to go home. An adverse event occurred in 101 patients (41\%), of whom 12 patients had an implantor surgery-related adverse event, and 13 patients sustained a wound infection. Other adverse events were a urinary tract infection, delirium, or various non-hip related adverse events, which were all infrequent (i.e., less than 10 patients each). In 38 patients (15\%) the implant was removed after the fracture had healed because of persisting implant-related complaints. A revision to an arthroplasty occurred in 67 patients (27\%), of which 45 patients received a total hip arthroplasty. Out of 67 patients that had a revision to arthroplasty, the revision had been performed in 52 patients by one year follow-up, in 36 patients by six months follow-up, and 
in 23 patients by ten weeks follow-up. The main reason for the revision surgery was the occurrence of avascular necrosis and/or non-union. The mean follow-up was 25.5 months (SD 6.1).

\section{Costs}

An overview of the costs is shown in Table 3. Most costs were generated in the first treatment year. The total mean costs per patient at 10 weeks follow-up amounted to $€ 9,781$ (SD $€$ 6,909). The costs in this primary treatment phase were mainly related to the primary surgery (mean €1,313; SD € 497), the hospital admission days (mean €4,322; SD €3,104), and the admission days in a rehabilitation center or skilled nursing facility after hospital discharge (mean €2,735; SD €5,226).

At one year follow-up, the total mean costs per patient were €16,379 (SD €17,319), $€ 6,598$ more than at 10 weeks follow-up. The total mean costs per patient in the second year of follow-up amounted $€ 3,046$. The total mean costs per patient after two years were on average $€ 19,425$ (SD $€ 24,200$ ). The main contributing cost categories in the first and second year of follow-up were similar: (1) the costs related to the admission days in a rehabilitation center or skilled nursing facility (i.e., €7,452 per patient in the first year and $€ 1,973$ in the second year), (2) the costs related to physical therapy at home or in an outpatient physical therapy clinic (i.e., €1,354 per patient in the first year and €496 in the second year), and (3) the costs of revision surgery and related hospital admission days (i.e., €512 per patient in the first year and $€ 195$ in the second year). In 5 patients, there were extremely high costs for the primary hospital admission (i.e., more than €10,000), mainly due to a prolonged length of stay. In three patients this was caused by multiple adverse events and revision surgeries, and an admission to the ICU. In two patients, no reason could be found for the prolonged length of stay. Radiologic studies and other diagnostic studies (i.e., €544; SD 343) and out-patient 
clinic visits (i.e., €452; SD 267) contributed more than one percent to the total treatment costs of the patients at two years follow-up (Figure 2).

At two years follow-up, the costs were highest for patients who underwent a revision to arthroplasty (total mean costs per patient €26,733; SD €24,151) (Table 4). Costs per patient were lowest for patients who did not require revision surgery; €17,405 (SD €25,842). Patients who had had their implant removed had lower costs (total mean costs per patient $€ 10,066$; SD $€ 5,484 ; \mathrm{P}$ 0.001). These differences were seen throughout all follow-up moments. 


\section{Discussion}

The total mean costs per femoral neck fracture patient treated with internal fixation were $€ 16,379$ at one year follow-up and $€ 19,425$ at two years follow-up. This is slightly higher than the $€ 13,600$ estimated in 1999 from national database records, including similar cost categories (cost corrected for inflation $€ 17,478$, using http://statline.cbs.nl) [6]. One should realize that the costs presented include crude costs only, excluding hospital overhead costs and taxes, as is usual for economic analyses. This should be taken into account when calculating budgets.

The cost estimates in our study are comparable with previous studies from Western societies, although other studies usually did not incorporate all cost categories that were included in the present study. This may indicate that the hip fracture care pathways as implemented in the Netherlands promoting early mobilization, early hospital discharge, and rehabilitation in a specialized nursing home department or at home lead to limited costs. The costs in our study are even $>50 \%$ lower than published costs in 2010 and 2012 for Norway (Table 1) [7-13]. Differences can be explained by several factors. The Norwegian studies involved older patients, all suffering from displaced fractures, and who were more often institutionalized pre-fracture, and less mobile without an aid pre-fracture, with more severe comorbidity (including the cognitively impaired). All patients were treated in a university hospital, which induces higher costs in general. Additionally, the unit costs per admission day to the hospital and to a nursing home were higher in Norway. The revision surgery rate in our study was comparable with previously published rates and will therefore not have influenced differences in costs between our study and previously published cost data [8, 13, 18-20].

The main determinant in the total costs was the costs for admission to a rehabilitation facility or nursing home. However, these costs may represent an overestimation of the actual 
cost related to the hip fracture. It is difficult to determine if the hip fracture was the only reason for temporary or permanent stay in a nursing home. Especially in elderly patients this is usually multifactorially influenced by general condition, other comorbidities or fractures, and the availability of informal care. Another important determinant was the costs for the primary hospital admission, similar as reported in other studies. In our study, the length of stay was shorter than in some other studies $[8,11,12]$. This distribution of costs in the Netherlands seems an effect of the hip fracture care pathways described above. Other determinants that substantially contributed to the total costs were the costs for primary surgery (7\%) and the costs for physical therapy in the out-patient clinic (10\%). Reducing the amount of physical therapy should not be a focus to reduce costs, as intensive physical therapy has proven to benefit patient outcomes and independency [21]. Most costs were generated in the first year. In the second year only $16 \%$ of the costs were generated. A two years follow-up was considered sufficient, as it is known that most interventions, treatments and rehabilitation of the targeted patient population will take place in that period [19]. A subset of patients, however, will become permanent nursing home residents after their hip fracture, thereby extending their societal costs beyond the two years time span. This may not only be caused by the hip fracture, as discussed above.

As expected, costs were highest for patients who underwent a revision to arthroplasty. After two years, the costs per patient were on average $€ 9,328$ per patient higher than for the patients that did not require revision surgery. This amount is in agreement with previous data, and is attributed to additional costs for surgery, hospital admission, and rehabilitation [8]. Baseline characteristics of the patients that underwent a revision to arthroplasty (i.e., age, comorbidity, and pre-fracture living status and mobility) were similar as for patients that did not. Costs were lowest for patients who had their implant removed after fracture healing. This may seem unexpected, as the implant removal is associated with costs for the surgical 
intervention. Patient selection is the most likely explanation for the relatively low costs. The implant removal patients were younger, healthier, more independent and mobile pre-fracture. They therefore probably required less care and rehabilitation, generating less costs. Their superior pre-fracture mobility and hence perhaps higher rehabilitation goals may also be an indication for their implant removal. Within the patient group that did not have a revision surgery, no potential factors were correlated with higher costs other than the previously mentioned patient characteristics (i.e., age, ASA score and mobility pre-fracture).

Our study has some limitations. As the population was relatively young, healthy, and independent pre-fracture, the presented costs may not be representative for all hip fracture patients. Moreover, not all cost categories related to hip fracture care were included. Costs of home care, informal care, and transport could not be reliably reproduced by patients. These costs are however expected not to contribute significantly to the total costs, compared with the costs that were included. Societal costs due to productivity losses were also excluded, but these are not expected to contribute significantly as well as these patients are older and mainly retired. Taking these limitations into account, the presented costs are probably an underestimation of the actual costs involved, especially for the patients that rehabilitated at home. However, the current study is one of few studies analyzing costs of hip fracture treatment with internal fixation in detail, including both hospital costs and costs of the rehabilitation process. Another strength of our study is the sample size, being the highest of all studies published until now.

In conclusion, the total mean costs per femoral neck fracture patient treated with internal fixation were $€ 16,379$ at one year follow-up and $€ 19,425$ at two years follow-up. These costs are comparable with costs published from previous studies in Western societies. The hip fracture care pathways implemented in the Netherlands promoting early mobilization, early 
hospital discharge, and rehabilitation in a specialized nursing home department or at home, seem successful and contributory to limiting health care costs. Highest costs are generated by patients who underwent a revision to arthroplasty. This reinforces the importance of attempting to reduce the potentially avoidable risk of a revision surgery by a careful selection of patients for internal fixation, not only for medical reasons, but also economical reasons. 


\section{Acknowledgments}

\section{FAITH trial study group:}

Steering Committee: Mohit Bhandari (Chair), Marc Swiontkowski, Philip J. Devereaux, Gordon Guyatt, Martin J. Heetveld, Kyle Jeray, Susan Liew, Emil H. Schemitsch, Lehana Thabane, Stephen Walter

Global Methods Centre: Mohit Bhandari (Principal Investigator); Sheila Sprague (Research Program Manager); Taryn Scott, Marilyn Swinton, Helena Viveiros (Research Coordination); Diane Heels-Ansdell, Qi Zhou (Statistical Analysis); Lisa Buckingham, Aravin Duraikannan (Data Management); Deborah Maddock (Grants Manager) (McMaster University)

US Methods Centre: Marc Swiontkowski (Principal Investigator); Julie Agel (Research Coordination) (University of Minnesota)

Netherlands Method Centre: Martin J. Heetveld (Principal Investigator); Esther M.M. Van Lieshout (Research Coordination); Stephanie M. Zielinski (Trial Coordination) (Erasmus MC, University Medical Center Rotterdam)

UK Methods Centre: Amar Rangan (Principal Investigator); Birgit Hanusch (Research Coordination) (The James Cook University Hospital)

Central Adjudication Committee: Gregory J Della Rocca (Chair), Robert Haverlag, Susan Liew, Gerard Slobogean 
Data Safety Monitoring Board: Jeffrey Katz (Chair), Brenda Gillespie, Gail A. Greendale, Pierre Guy, Curtis Hartman, Craig Rubin, James Waddell

Netherlands Cost analysis support: Clazien A.M. Bouwmans, Elly A. Stolk, Martijn Kroonen, Hamza Jap-Tjong (Institute for Medical Technology Assessment, Erasmus University

\section{Rotterdam)}

\section{Clinical Site Investigators}

The following persons participated in the FAITH Study:

Canada:

Robert McCormack, Kelly Apostle, Dory Boyer, Farhad Moola, Bertrand Perey, Trevor Stone, Darius Viskontas, H. Michael Lemke, Mauri Zomar, Karyn Moon, Raely Moon, Amber Oatt (Royal Columbian Hospital); Richard E. Buckley, Paul Duffy, Robert Korley, Shannon Puloski, Kelly Johnston, James Powell, Kimberly Carcary (Foothills Medical Centre); David Sanders, Abdel Lawendy, Christina Tieszer (London Health Sciences Centre); David Stephen, Hans Kreder, Richard Jenkinson, Markku Nousiainen, Terry Axelrod, John Murnaghan, Diane Nam, Robin Richards,. Sebastian Rodriguez-Elizalde, Veronica Wadey, Albert Yee, Katrine Milner, Monica Kunz, Melanie MacNevin, Ria Cagaanan (Sunnybrook Health Sciences Centre); Ryan Bicknell, Jeff Yach, Davide Bardana, Gavin Wood, Mark Harrison, David Yen, Sue Lambert, Fiona Howells, Angela Ward (Human Mobility Research Centre, Queen’s University and Kingston General Hospital); Chad Coles, Ross Leighton, Michael Biddulph, David Johnston, Mark Glazebrook, David Alexander, Cathy Coady, Michael Dunbar, Kelly Trask, Shelley MacDonald, Gwen Dobbin (Queen Elizabeth II Health Sciences Centre); Emil H. Schemitsch, Henry Ahn, Jeremy A Hall, Michael D McKee, Daniel B Whelan, Aaron Nauth, 
Milena Vicente, Lisa Wild, Ryan Khan, and Jennifer Hidy (St. Michael’s Hospital); Paul Zalzal, Heather Brien, V. Naumetz, Brad Weening, Nicole Simunovic (Oakville Trafalgar Memorial Hospital); Eugene K. Wai, Steve Papp, Wade T. Gofton, Allen Liew, Stephen P. Kingwell, Darren M. Roffey, Vivian Borsella (Ottawa Hospital); Victoria Avram (Juravinski Hospital and Cancer Centre)

\section{United States:}

Todd M. Oliver, Vicki Jones (Boone Hospital Center - Columbia Orthopaedic Group); Clifford Jones, James Ringler, Terrence Endres, Debra L. Sietsema (Orthopaedics Associates of Michigan); Kyle J. Jeray, J. Scott Broderick, David R. Goetz, Thomas B. Pace, Thomas M. Schaller, Scott E. Porter, Stephanie L. Tanner, Rebecca G. Snider, Lauren A. Nastoff, Shea A. Bielby (Greenville Hospital System); Andrew J Marcantonio, Richard Iorio, John Garfi (Lahey Clinic); Michael J. Prayson, Richard Laughlin, Joseph Rubino, Jedediah May, Geoffrey Ryan Rieser, Liz Dulaney-Cripe, Chris Gayton (Miami Valley Hospital); Julie A. Switzer, Peter A. Cole, Sarah A. Anderson, Paul M. Lafferty, Mengnai Li, Thuan V. Ly, Scott B. Marston, Amy L. Foley, Sandy Vang, David M. Wright (Regions Hospital-University of Minnesota); Heather A. Vallier, Andrea Dolenc, Chalitha Robinson (MetroHealth Medical Center); John T. Gorczyca, Jonathan M. Gross, Catherine A. Humphrey, Stephen Kates, Krista Noble, Allison W McIntyre, Kaili Pecorella (University of Rochester Medical Center); James Shaer, Tyson Schrickel, Barbara Hileman (St. Elizabeth Health Center); Craig A. Davis, Stewart Weinerman, Peter Weingarten, Philip Stull, Stephen Lindenbaum, Michael Hewitt, John Schwappach, Janell K. Baker (Colorado Orthopedic Consultants); Samir Mehta, John Esterhai, Jaimo Ahn, Annamarie D. Horan, Kelly McGinnis, Christine A. Kaminski, Brynn N. Kowalski (University of Pennsylvania); Lisa K. Cannada, David Karges, Leslie Hill (St. Louis 
University Hospital); Ivan Tarkin, Peter Siska, Gary Gruen, Andrew Evans, Dana J. Farrell, James Irrgang, Arlene Luther (University of Pittsburgh Medical Center); Jonathan P. Keeve, Christopher G. Anderson, Michael D. McDonald, Jodi M. Hoffman (Northwest Orthopaedic Specialists); Mark Jenkins, Jules Dumais, Amanda W. Romero (Texas Tech University Health Sciences Center - Lubbock); Joseph R. Hsu, James Ficke, Michael Charlton, Matthew Napierala, Mary Fan (US Army Institute of Surgical Research); William W. Cross III, Joseph R. Cass, Stephen A. Sems, Michael E. Torchia, Tyson Scrabeck (Mayo Clinic); Carlos A. Sagebien, Mark S. Butler, James T. Monica, Patricia Seuffert (University Orthopaedic Associates, LLC); Michael L. Brennan, Robert Probe, Evelyn Kile, Kelli Mills, Lydia Clipper, Michelle Yu, Katie Erwin (Scott and White Memorial Hospital); Paul Tornetta III, Hope Carlisle, Heather Silva (Boston University Medical Center); Michael Archdeacon, Ryan Finnan, Toan Le, John Wyrick, Shelley Hess (UC Health/University of Cincinnati Medical Center); Jessica McBeth (Santa Clara Valley Medical Center); Kamran Aurang, Gary Zohman, Brett Peterson, Roger B. Huff, (Kaiser Permanente); Joseph Baele, Timothy Weber, Matt Edison (OrthoIndy); Andrew H. Schmidt, Jerald R. Westberg (Hennepin County Medical Center); Charles J. DePaolo, Rachel Alosky, Leslie E. Shell, Lynne Hampton, Stephanie Shepard, Tracy Nanney, Claudine Cuento (Mission Hospital Research Institute); Karl Shively, Janos P. Ertl, Brian Mullis, J. Andrew Parr, Ripley Worman, Valda Frizzell, Molly M. Moore, Erin Tobias, Emily Thomas (Indiana University - Wishard Health Services); Robert V. Cantu, Eric R. Henderson, Linda S. Eickhoff (Dartmouth-Hitchcock Medical Center); David P. Zamorano, Deeba Pourmand, Deanna Lawson (University of California Irvine Medical Center); E. Mark Hammerberg, Philip Stahel, David Hak, Cyril Mauffrey, Douglas Gibula, Hannah Gissel, Corey Henderson (Denver Health Medical Center); Gregory J. Della Rocca, Brett D. Crist, Yvonne M. Murtha, Melinda McPherson, Linda K. Anderson (University of 
Missouri Health Care); Michael P. Dohm, Abby Zellar (Western Slope Study Group);

Colleen Linehan, Lindsey Pilling (Covenant Healthcare of Saginaw) Daniel Horwitz, Kent

Strohecker (Geisinger Medical Center); Courtland G. Lewis, Stephanie Caminiti, Raymond

J. Sullivan, Elizabeth Roper (University of Connecticut - Hartford Hospital); William

Obremskey, Philip Kregor, Justin E. Richards, Kenya Stringfellow (Vanderbuilt University

\section{Medical Center)}

The Netherlands:

J. Carel Goslings, Robert Haverlag, Kees Jan Ponsen. (Academic Medical Center); Maarten

W.G.A. Bronkhorst, Onno R. Guicherit (Bronovo Ziekenhuis); Peter Patka, Martin G.

Eversdijk, Rolf Peters, Dennis Den Hartog, Oscar J.F. Van Waes, Pim Oprel (Erasmus MC,

University Medical Center Rotterdam); Piet A.R. de Rijcke, Cees L. Koppert, Steven E.

Buijk, Richard P.R. Groenendijk, Imro Dawson, Geert W.M. Tetteroo, Milko M.M.

Bruijninckx, Pascal G. Doornebosch, Eelco J.R. de Graaf (IJsselland Ziekenhuis); Martin J.

Heetveld, Gijs A. Visser, Heyn Stockmann, Rob Silvis, Jaap P. Snellen, Bram Rijbroek, Joris J.G. Scheepers, Erik G.J. Vermeulen, Michiel P.C. Siroen, Ronald Vuylsteke, Hans L.F. Brom, Herman Rijna (Kennemer Gasthuis); Gert R Roukema, Hong Josaputra, Paul Keller, Peter D. de Rooij, Hans Kuiken, Han Boxma, Berry I. Cleffken, Ronald Liem (Maasstad Ziekenhuis); Steven J. Rhemrev, Coks H.R. Bosman, Alexander de Mol van Otterloo, Jochem Hoogendoorn, Alexander C. de Vries, Sven A.G. Meylaerts (Medisch Centrum Haaglanden); Rudolf W. Poolman, Maarten P. Simons, Frank H.W.M. van der Heijden, W. Jaap Willems, Frank R.A.J. de Meulemeester, Cor P. van der Hart, Kahn Turckan, Sebastiaan Festen, Frank de Nies, Robert Haverlag, Nico J.M. Out, Jan Bosma (Onze Lieve Vrouwe Gasthuis); Maarten van der Elst, Carmen C. van der Pol, Martijne van ’t Riet, Tom M. Karsten, Mark R. de Vries, Laurents P.S. Stassen, Niels W.L. Schep, G. Ben Schmidt, W.H. 
Hoffman (Reinier de Graaf Gasthuis); Michiel J.M. Segers, Jacco A.C. Zijl, Bart

Verhoeven, Anke B. Smits, Jean Paul P.M. de Vries, Bram Fioole, Henk van der Hoeven, Evert B.M. Theunissen, Tammo S. de Vries Reilingh, Lonneke Govaert, Philippe Wittich, Maurits de Brauw, Jan Wille, Peter M.N.Y.M. Go, Ewan D. Ritchie, Ronald N. Wessel, Eric R. Hammacher (St. Antonius Ziekenhuis); Michiel H.J. Verhofstad, Joost Meijer, Teun van Egmond, Frank H.W.M. van der Heijden, Igor van der Brand (St. Elisabeth Ziekenhuis); Harm M van der Vis, Martin Campo, Ronald Verhagen, G.H. Robert Albers, Arthur W. Zurcher (Tergooi Ziekenhuizen); Albert van Kampen, Jan Biert, Arie B. van Vugt, Michael J.R. Edwards, Taco J. Blokhuis, Jan Paul M. Frölke, Leo M.G. Geeraedts, Jean W.M. Gardeniers, Edward T.C.H. Tan, Lodewijk M.S.J. Poelhekke, Maarten C. de Waal Malefijt, Bart Schreurs (University Medical Center St. Radboud); Rogier K.J. Simmermacher, Jeroen van Mulken, Karlijn van Wessem, Taco J. Blokhuis, Steven M. van Gaalen, Luke P.H. Leenen (University Medical Center Utrecht)

\section{International:}

Susan Liew, Harvinder Bedi, Ashley Carr, Andrew Chia, Steve Csongvay, Hamish Curry, Stephen Doig, Craig Donohue, Elton Edwards, Greg Etherington, Andrew Gong, Arvind Jain, Doug Li, Russell Miller, Ash Moaveni, Matthias Russ, Lu Ton, Otis Wang, Zoe Murdoch, Claire Sage (The Alfred, Australia); Frede Frihagen, John Clarke-Jenssen, Geir Hjorthaug, Torben Ianssen, Asgeir Amundsen, Jan Egil Brattgjerd, Tor Borch, Berthe Bøe, Bernhard Flatøy, Sondre Hasselund, Knut Jørgen Haug, Kim Hemlock, Tor Magne Hoseth, Geir Jomaas, Thomas Kibsgård, Bjørn Kristiansen, Tarjei Lona, Gilbert Moatshe, Oliver Müller, Marius Molund, Tor Nicolaisen, Fredrik Nilsen, Jonas Rydinge, Morten Smedsrud, Are Stødle, Axel Trommer, Stein Ugland, Elise Berg Vesterhus, Anne Christine Brekke (Ulleval University Hospital, Norway); Ateet Sharma, Amir Sanghavi (Satellite Orthopaedic 
Hospital and Research Centre, India); Kevin Tetsworth, Donald Geoff, Patrick Weinrach, Paul Pincus, Steven Yang, Brett Halliday, Trevor Gervais, Michael Holt, Annette Flynn (Royal Brisbane and Women’s Hospital, Australia); Amal Shankar Prasad, Vimlesh Mishra (Madhuraj Nursing Home, India); Ajay Gupta, Niraj Jain (Nirmal Hospital, India); Mahesh Bhatia, Vinod Arora, Mahesh Bhatia (RLB Hospital and Research Centre, India); D.C. Sundaresh, Angshuman Khanna (M.S. Rammaiah Medical College \& Hospital, India); Anil Rai, Subash (Highway Hospital, India); Marinis Pirpiris, David Love, Andrew Bucknill, Richard J Farrugia (Royal Melbourne Hospital, Australia); Akhil Dadi, Naveen Palla (Sunshine Hospital, India); B. Sachidananda Rai, Janakiraman Rajakumar (Unity Health Complex, India); Joe Joseph Cherian, Davy J Olakkengil, Gaurav Sharma (St John's Medical College Hospital, India) 


\section{References}

1. Gullberg B, Johnell, O, Kanis, JA (1997) World-wide projections for hip fracture. Osteoporos Int 7:407-413.

2. Johnell O (1997) The socioeconomic burden of fractures: today and in the 21st century. Am J Med 103:20S-25S; discussion 25S-26S.

3. Johnell O, Kanis, JA (2006) An estimate of the worldwide prevalence and disability associated with osteoporotic fractures. Osteoporos Int 17:1726-1733.

4. $\quad$ wwwkiwaprismantnl Last accessed at 21st August 2012.

5. Hartholt KA, Oudshoorn, C, Zielinski, SM, Burgers, PTPW, Panneman, MJ, van Beeck, EF, Patka, P, van der Cammen, TJ (2011) The epidemic of hip fractures: are we on the right track? PLoS One 6:e22227.

6. Meerding WJ, Mulder, S, van Beeck, EF (2006) Incidence and costs of injuries in The Netherlands. Eur J Public Health 16:272-278.

7. Alolabi B, Bajammal, S, Shirali, J, Karanicolas, PJ, Gafni, A, Bhandari, M (2009)

Treatment of displaced femoral neck fractures in the elderly: a cost-benefit analysis. J Orthop Trauma 23:442-446.

8. Frihagen F, Waaler, GM, Madsen, JE, Nordsletten, L, Aspaas, S, Aas, E (2010) The cost of hemiarthroplasty compared to that of internal fixation for femoral neck fractures. 2year results involving 222 patients based on a randomized controlled trial. Acta Orthop 81:446-452.

9. Haentjens P, Autier, P, Barette, M, Boonen, S (2003) Costs of care after hospital discharge among women with a femoral neck fracture. Clin Orthop Relat Res 250-258.

10. Iorio R, Healy, WL, Lemos, DW, Appleby, D, Lucchesi, CA, Saleh, KJ (2001) Displaced femoral neck fractures in the elderly: outcomes and cost effectiveness. Clin Orthop Relat Res 229-242. 
11. Johansson T, Bachrach-Lindstrom, M, Aspenberg, P, Jonsson, D, Wahlstrom, O (2006) The total costs of a displaced femoral neck fracture: comparison of internal fixation and total hip replacement. A randomised study of 146 hips. Int Orthop 30:1-6.

12. Rogmark C, Carlsson, A, Johnell, O, Sembo, I (2003) Costs of internal fixation and arthroplasty for displaced femoral neck fractures: a randomized study of 68 patients. Acta Orthop Scand 74:293-298.

13. Waaler Bjornelv GM, Frihagen, F, Madsen, JE, Nordsletten, L, Aas, E (2012) Hemiarthroplasty compared to internal fixation with percutaneous cannulated screws as treatment of displaced femoral neck fractures in the elderly: cost-utility analysis performed alongside a randomized, controlled trial. Osteoporos Int 23:1711-1719.

14. Hakkaart-van Roijen L (2002) Manual Trimbos/iMTA questionnaire for costs associated with psychaitric illness (in Dutch). In. Institute for Medical Technology Assessment, Rotterdam.

15. Bouwmans C, De Jong, K, Timman, R, Zijlstra-Vlasveld, M, Van der Feltz-Cornelis, C, Tan, SS, Hakkaart-van Roijen, L (2013) Feasibility, reliability and validity of a questionnaire on healthcare consumption and productivity loss in patients with a psychiatric disorder (TiC-P). BMC Health Serv Res 13:217.

16.

http://www.bmg.eur.nl/english/imta/publications/questionnaires_manuals/ipcq_and_i mcq/). Last accessed on March 15, 2013.

17. Hakkaart-van Roijen L, Tan, S.S., Bouwmans, C.A.M. (ed) (Geactualiseerde versie 2010.) Handleiding voor kostenonderzoek, methoden en standaard kostprijzen voor economische evaluaties in de gezondheidszorg. College voor zorgverzekeringen. 18. Bhandari M, Devereaux, PJ, Swiontkowski, MF, Tornetta, P, 3rd, Obremskey, W, Koval, KJ, Nork, S, Sprague, S, Schemitsch, EH, Guyatt, GH (2003) Internal fixation 
compared with arthroplasty for displaced fractures of the femoral neck. A meta-analysis. $\mathrm{J}$ Bone Joint Surg Am 85-A:1673-1681.

19. Blomfeldt R, Tornkvist, H, Ponzer, S, Soderqvist, A, Tidermark, J (2005) Internal fixation versus hemiarthroplasty for displaced fractures of the femoral neck in elderly patients with severe cognitive impairment. J Bone Joint Surg Br 87:523-529.

20. Heetveld MJ, Rogmark, C, Frihagen, F, Keating, J (2009) Internal fixation versus arthroplasty for displaced femoral neck fractures: what is the evidence? J Orthop Trauma 23:395-402.

21. Binder EF, Brown, M, Sinacore, DR, Steger-May, K, Yarasheski, KE, Schechtman, KB (2004) Effects of extended outpatient rehabilitation after hip fracture: a randomized controlled trial. JAMA 292:837-846. 
Tables

Table 1. Studies describing the costs of treatment of femoral neck fracture patients with internal fixation

\begin{tabular}{lllll}
\hline Author & Country & N & Follow-up & Average costs per patient \\
\hline Iorio et al. (2001) & US & 123 & 2 yrs & $€ 27,474^{\text {a }}$ \\
Haentjens et al. (2003) & Belgium & 14 & $1 \mathrm{yr}$ & $€ 15,255^{\text {a }}$ \\
Rogmark et al. (2003) & Sweden & 36 & $2 \mathrm{yrs}$ & $€ 18,564^{\text {a }}$ \\
Johansson et al. (2006) & Sweden & 78 & $2 \mathrm{yrs}$ & $€ 13,100$ \\
Alolabi et al. (2009) & Canada & 61 & $1 \mathrm{yr}$ & $€ 12,977^{\text {a }}$ \\
Frihagen et al. (2010) & Norway & 112 & $2 \mathrm{yrs}$ & $€ 47,186$ \\
Waaler Bjørnelv et al. (2012) & Norway & 86 & $2 \mathrm{yrs}$ & $€ 57,197$
\end{tabular}

${ }^{\mathrm{a}}$ US Dollars were converted to Euros using year-specific exchange rates (www.statistics.dnb.nl) 
Table 2. Sources and unit costs (2010) of healthcare resources

\begin{tabular}{|c|c|c|c|c|}
\hline Cost categories & Unit & Source of consumption data & Source of valuation & Unit price $(€)$ \\
\hline \multicolumn{5}{|l|}{ Hospital costs - primary stay } \\
\hline Emergency department visit & Visit & Hospital registry & Cost manual ${ }^{1}$ & 152.92 \\
\hline \multicolumn{5}{|l|}{ Radiology/Diagnostic studies } \\
\hline X-ray & X-ray & Hospital registry & $\mathrm{NZa}^{2}$ & 51.63 \\
\hline CT-scan pelvis & CT-scan & Hospital registry & $\mathrm{NZa}^{2}$ & 227.22 \\
\hline MRI scan pelvis & MRI scan & Hospital registry & $\mathrm{NZa}^{2}$ & 261.47 \\
\hline Ultrasound & Ultrasound & Hospital registry & $\mathrm{NZa}^{2}$ & 82.09 \\
\hline DEXA scan & DEXA scan & Hospital registry & $\mathrm{NZa}^{2}$ & 109.22 \\
\hline Skeletal scintigraphy & Scintigraphy & Hospital registry & $\mathrm{NZa}^{2}$ & 185.37 \\
\hline \multicolumn{5}{|l|}{ Surgery } \\
\hline Surgeon & Hour & Study registry (Case report Form) & Cost manual ${ }^{1}$ & $137.22^{\mathrm{a}} / 104.31^{\mathrm{b}}$ \\
\hline Operating room* & Hour & Study registry (Case report Form) & Hospital/industry data ${ }^{3}$ & $560.94^{\mathrm{a}} / 704.51^{\mathrm{b}}$ \\
\hline Additional costs after hours & Hour & Study registry (Case report Form) & Hospital/industry data ${ }^{3}$ & $75.36^{\mathrm{a}} / 94.65^{\mathrm{b}}$ \\
\hline Equipment and implant & & & & \\
\hline
\end{tabular}




\begin{tabular}{|c|c|c|c|c|}
\hline Cancellous screws & Operation & Study registry (Case report Form) & Hospital/industry data ${ }^{3}$ & 490.30 \\
\hline Sliding Hip Screw & Operation & Study registry (Case report Form) & Hospital/industry data ${ }^{3}$ & 504.91 \\
\hline Admission days & Day & Study registry (Case report Form) & Cost manual $^{1}$ & $440.53^{\mathrm{a}} / 582.31^{\mathrm{b}}$ \\
\hline \multicolumn{5}{|l|}{ Hospital costs - follow-up } \\
\hline Radiology/Diagnostic studies & & & & As described above \\
\hline Out-patient clinic visits & Visit & Hospital registry + patient questionnaire ${ }^{\S}$ & Cost manual $^{1}$ & $130.64^{\mathrm{a}} / 64.81^{\mathrm{b}}$ \\
\hline \multicolumn{5}{|l|}{ Adverse events } \\
\hline Medication** & Dose per day & Hospital registry + patient questionnaire ${ }^{\S}$ & $\mathrm{CVZ}^{4}$ & N.A. \\
\hline Emergency department visit & Visit & Hospital registry & Cost manual $^{1}$ & 152.92 \\
\hline Admission days & Day & Study registry (Case report Form) & Cost manual $^{1}$ & $440.53^{\mathrm{a}} / 582.31^{\mathrm{b}}$ \\
\hline \multicolumn{5}{|l|}{ Revision surgery } \\
\hline Surgeon & Hour & Study registry (Case report Form) & Cost manual ${ }^{1}$ & $137.22^{\mathrm{a}} / 104.31^{\mathrm{b}}$ \\
\hline Operating room* & Hour & Study registry (Case report Form) & Hospital/industry data ${ }^{3}$ & $560.94^{\mathrm{a}} / 704.51^{\mathrm{b}}$ \\
\hline \multicolumn{5}{|l|}{ Equipment and implant } \\
\hline Hemiarthroplasty & Operations & Study registry & Hospital/industry data ${ }^{3}$ & 1685.64 \\
\hline Total Hip Arthroplasty & Operations & Study registry & Hospital/industry data ${ }^{3}$ & 1722.39 \\
\hline
\end{tabular}




\begin{tabular}{|c|c|c|c|c|}
\hline Gammanail & Operations & Study registry & Hospital/industry data ${ }^{3}$ & 1241.51 \\
\hline Extended gammanail & Operations & Study registry & Hospital/industry data ${ }^{3}$ & 1258.39 \\
\hline Implant removal & Operations & Study registry & Hospital/industry data ${ }^{3}$ & 53.16 \\
\hline Soft tissue debridement & Operations & Study registry & Hospital/industry data ${ }^{3}$ & 25.29 \\
\hline Antibiotic beads & Operations & Study registry & Hospital/industry data ${ }^{3}$ & 567.79 \\
\hline Antibiotic spacer & Operations & Study registry & Hospital/industry data ${ }^{3}$ & 496.26 \\
\hline Admission days & Day & Study registry (Case report Form) & Cost manual ${ }^{1}$ & $440.53^{\mathrm{a}} / 582.31^{\mathrm{b}}$ \\
\hline Medication*** & Dose per day & Hospital registry + patient questionnaire ${ }^{\S}$ & $\mathrm{CVZ}^{4}$ & N.A. \\
\hline \multicolumn{5}{|l|}{ Costs related to rehabilitation / } \\
\hline \multicolumn{5}{|l|}{ changes in living situation } \\
\hline \multicolumn{5}{|l|}{ Rehabilitation center/Nursing home } \\
\hline Elderly home & Days & Patient questionnaire ${ }^{\S}$ & Cost manual ${ }^{1}$ & 91.14 \\
\hline Nursing home & Days & Patient questionnaire ${ }^{\S}$ & Cost manual $^{1}$ & 241.03 \\
\hline Rehabilitation clinic & Days & Patient questionnaire $e^{\S}$ & Cost manual $^{1}$ & 344.32 \\
\hline Home nursing day & Hours & Patient questionnaire ${ }^{\S}$ & Cost manual $^{1}$ & 35.44 \\
\hline Physical therapy (outpatient) & & & & \\
\hline
\end{tabular}




\begin{tabular}{|c|c|c|c|c|}
\hline Physical therapy & Session & Patient questionnaire $^{\S}$ & Cost manual $^{1}$ & 36.46 \\
\hline Mensendieck / Cesar therapy & Session & Patient questionnaire $^{\S}$ & Cost manual $^{1}$ & 35.45 \\
\hline \multicolumn{5}{|l|}{ Use of aids } \\
\hline Crutches & Day & Patient questionnaire ${ }^{\S}$ & Home care firm ${ }^{5}$ & 0.07 \\
\hline Walker & Day & Patient questionnaire ${ }^{\S}$ & Home care firm ${ }^{5}$ & $0.08-0.14$ \\
\hline Wheelchair & Day & Patient questionnaire ${ }^{\S}$ & Home care firm ${ }^{5}$ & 0.25 \\
\hline Electric scooter & Day & Patient questionnaire ${ }^{\S}$ & Home care firm ${ }^{5}$ & 0.66 \\
\hline Extra bed & Day & Patient questionnaire $^{\S}$ & Home care firm ${ }^{5}$ & 1.15 \\
\hline Extra toilet facilities & Day & Patient questionnaire ${ }^{\S}$ & Home care firm ${ }^{5}$ & $0.09-0.19$ \\
\hline Extra shower facilities & Day & Patient questionnaire ${ }^{\S}$ & Home care firm ${ }^{5}$ & $0.09-0.17$ \\
\hline
\end{tabular}

N.A.; Not applicable

Reference unit costs anno 2010 were used, or costs were adjusted to 2010 costs using the national consumer price index.

*Including operating room personnel, anesthesia, and overhead costs. **Mainly antibiotics. ***Hip fracture related medication only (i.e., pain medication and osteoporosis medication; see Supplemental Table 2 for details).

§ Patient questionnaire; Customized version of the 'Trimbos and iMTA questionnaire on Costs associated with Psychiatric illness'. 
${ }^{1}$ Cost manual; Manual on cost research, methods and standard costs in economic healthcare evaluations, version 2010 (17), ${ }^{2}$ NZa; Nederlandse Zorgautoriteit (Dutch Healthcare Authority) standard costs. ${ }^{3}$ Hospital/industry data; costs were requested from one academic hospital, three regional hospitals, and one surgical equipment and implant firm. Means were calculated and used as an estimation of the real costs in all participating sites. ${ }^{4}$ CVZ; Standard prices were used as described by the CVZ (College voor zorgverzekeringen; Health Care Insurance Board), online available on www.medicijnkosten.nl. ${ }^{5}$ Home care firm; costs of aids were requested from a home care firm and costs per day were calculated based on the calculated daily annuity. These costs were used as an estimation of the real costs in all participating patients.

${ }^{\mathrm{a}}$ Academic hospital, ${ }^{\mathrm{b}}$ General hospital. 
Table 3. Mean costs of femoral neck fracture patients treated with internal fixation $(\mathrm{N}=\mathbf{2 4 8})$

\begin{tabular}{|c|c|c|c|}
\hline Cost categories & Cost until 10 weeks (€) & Costs until 1 year $(€)$ & Costs until 2 years $(€)$ \\
\hline \multicolumn{4}{|l|}{ Hospital costs - primary stay } \\
\hline Emergency department visit & $152(152-152)$ & $152(152-152)$ & $152(152-152)$ \\
\hline Radiology/Diagnostic modalities & $243(207-361)$ & $243(207-361)$ & $243(207-361)$ \\
\hline Surgery & $1,313(793-2,506)$ & $1,313(793-2,506)$ & $1,313(793-2,506)$ \\
\hline Admission days & 4,322 (1,762-9,287) & $4,322(1,762-9,287)$ & 4,322 (1,762-9,287) \\
\hline Total & 6,031 (3,392-11,090) & $6,031(3,392-11,090)$ & $6,031(3,392-11,090)$ \\
\hline \multicolumn{4}{|l|}{ Hospital costs - follow-up } \\
\hline Radiology/Diagnostic modalities & $212(103-472)$ & $441(127-981)$ & $544(207-1,163)$ \\
\hline Out-patient clinic visits & $134(65-261)$ & $370(165-792)$ & $452(194-1,023)$ \\
\hline Adverse events & $39(0-45)$ & $54(0-111)$ & $128(0-697)$ \\
\hline Revision surgery & $154(0-1500)$ & $512(0-2,117)$ & $707(0-2,287)$ \\
\hline Medication & $30(0-112)$ & $88(0-324)$ & $157(0-555)$ \\
\hline Total & $568(168-1,989)$ & $1,465(378-4171)$ & $1,988(480-4,838)$ \\
\hline Costs related to rehabilitation / & & & \\
\hline
\end{tabular}




\begin{tabular}{lccc}
\hline changes in living situation & & & \\
Rehabilitation center/Nursing home & $2,735(0-15,076)$ & $7,452(0-39,991)$ & $9,425(0-46,308)$ \\
Physical therapy (outpatient) & $418(0-1006)$ & $1,354(231-3,169)$ & $1,850(292-4,752)$ \\
Use of aids & $28(5-104)$ & $76(5-245)$ & $131(5-466)$ \\
Total & $3,181(27-15,782)$ & $8,883(487-41,743)$ & $11,406(540-51,300)$ \\
Total costs & $9,781(3,993-24,203)$ & $16,379(4,977-52,339)$ & $19,425(5,237-58,874)$
\end{tabular}

Costs are presented as cumulative mean costs at each follow-up moment with 95\% confidence interval between brackets. 
Table 4. Costs of patients without revision surgery, patients who had an implant removal, and patients who required revision surgery

\section{No revision surgery}

\section{Implant removed*}

$(\mathrm{N}=38)$

$\begin{array}{rr}9,371(3,970-24,339) & 6,967(3,394-19,322) \\ 14,438(4,824-45,211) & 8,723(4,434-19,735) \\ 17,405(4,953-58,865) & 10,066(4,843-26,731)\end{array}$

Costs until 2 years
Costs until 10 wks

\begin{abstract}
Costs are presented
\end{abstract}
Differences between the three groups were compared with a one-way ANOVA. Post-hoc comparisons using independent samples student T-tests were performed and indicated that all subgroups had significant differences in costs at all follow-up moments (i.e., $\mathrm{P}<0.005)$.

Six patients were excluded from the subgroup analyses as these patients all had other, less common, revision surgeries (i.e., replacement of implant by other implant, shorter screw, or revision to gamma nail)

* This group consisted of patients that healed successfully.

$\begin{array}{ll}11,549(5,125-29,762) & 0.003 \\ 22,498(8,052-73,307) & <0.001 \\ 26,733(9,465-80,029) & 0.001\end{array}$

Revision surgery to arthroplasty $\quad$ P-value

$$
(\mathrm{N}=67)
$$


Figures

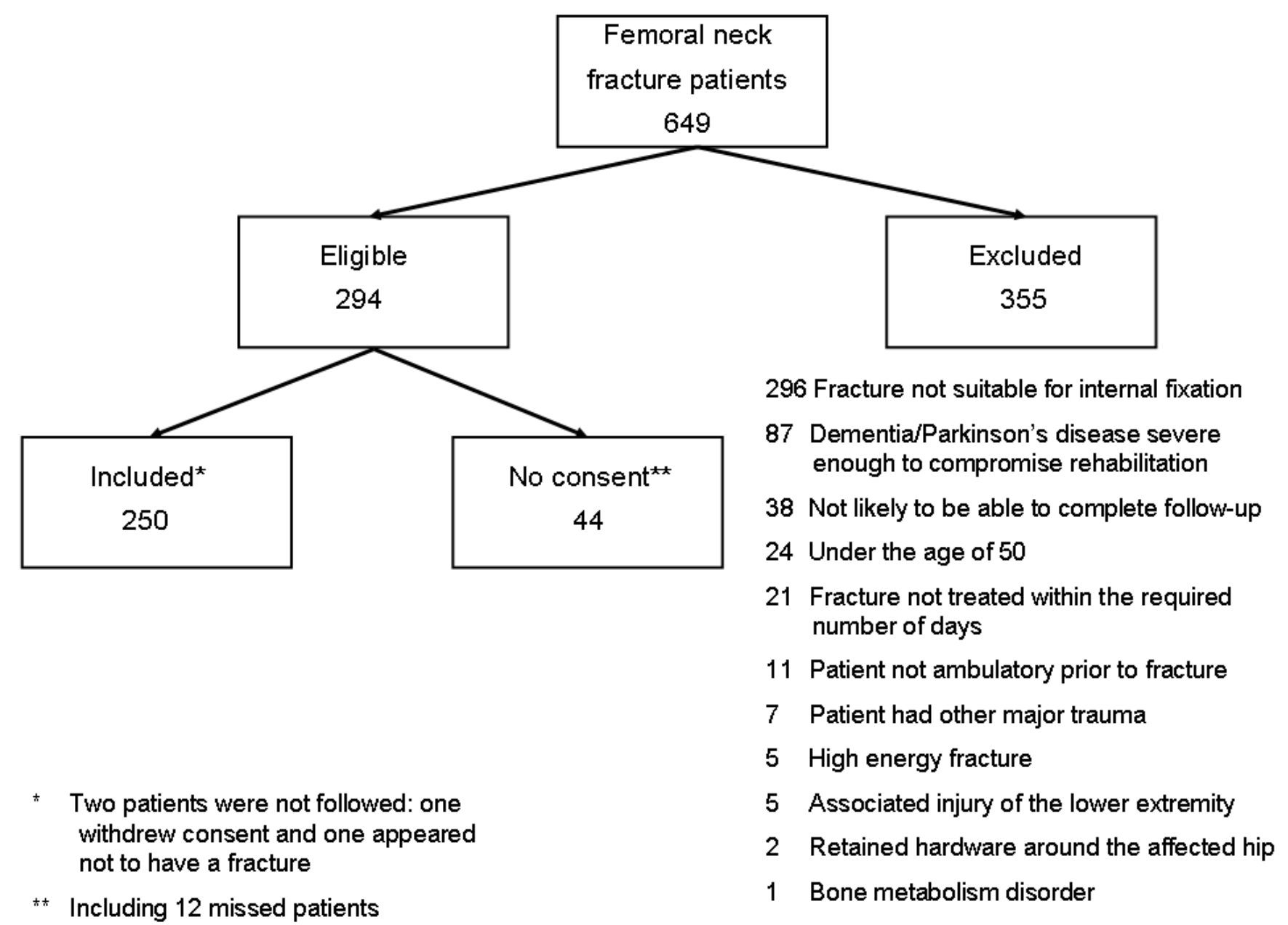

Figure 1. Flowchart of patients participating in the study 


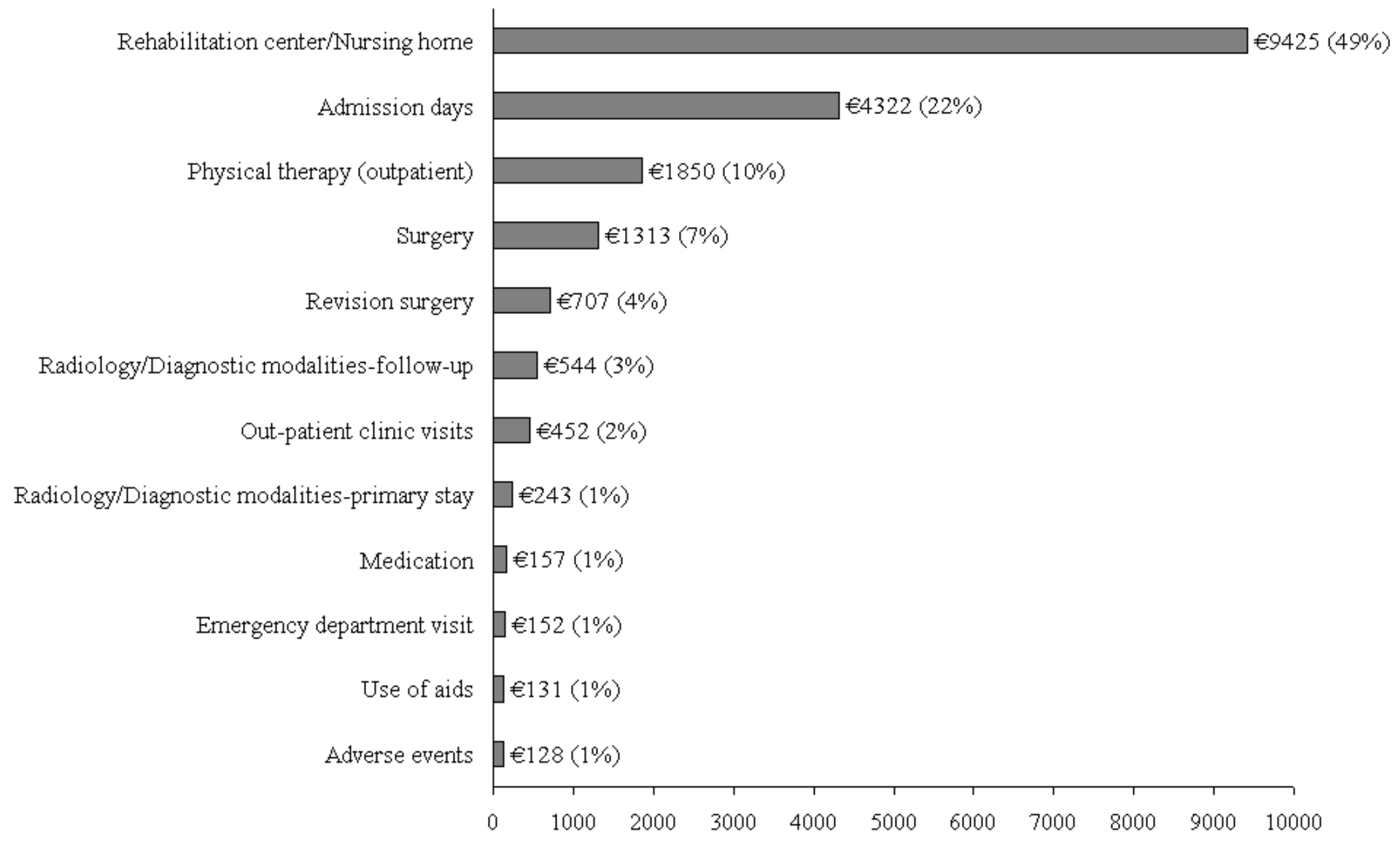

Figure 2. Relative contribution of various cost categories to the total treatment costs of patients until two years follow-up. 